\title{
Method for Efficient Regeneration of Solvent Mixture: Extractive Heterogeneous-Azeotropic Distillation
}

\author{
András József TÓTH, ${ }^{1}$ Szilvia SCHMIDT ${ }^{2}$ \\ BME-VBK Department of Chemical and Environmental Process Engineering, Environmental and Process \\ Engineering Research Group, Budapest, Hungary \\ ${ }^{1}$ andrasjozseftoth@edu.bme.hu \\ ${ }^{2}$ schmidt.szilvia@edu.bme.hu
}

\begin{abstract}
The fine chemical and pharmaceutical industries use large amounts of various organic solvents in their manufacturing processes. By reusing them, production costs can be significantly reduced. If we can regenerate waste solvent mixtures, we have the opportunity to reuse them in the production process or in other production processes. Our study illustrates an efficient regeneration process using the example of a four-component solvent mixture. Calculations were performed in a professional process simulator to demonstrate that the highly non-ideal Water-Ethyl Alcohol-Methyl Ethyl Ketone-Ethyl Acetate solvent mixture can be efficiently decomposed into azeotropic pairs and thus regenerated by the extractive heterogeneous-azeotropic distillation technique.
\end{abstract}

Keywords: solvent mixture, process simulator, extractive heterogeneous-azeotropic distillation.

\section{Introduction}

On our planet, industrial processes require increasingly more careful planning and operation. This thinking requires the mimicking of nature's cycles and the transposition of the concept of cycles into industrial practice, since there is no waste in nature, everything is always utilized [1].

It is important to emphasize that the energy recovery and disposal of waste is either not cheap or not efficient in terms of environmental sustainability. As these methods return chemicals to our natural environment, it is advisable to set up our waste management strategy from the tools above them in the hierarchy [2]. It is advisable to follow the procedures for reuse and recycling in the waste management hierarchy diagram shown in Figure 1.

In the recent period, environmental protection has also become increasingly important in the chemical industry. Although the goal in environmental process planning is to prevent the generation of waste, in many cases it is inevitable that waste will be generated. A typical example of this is the case of process wastewater and residual solvents, which are generated especially in the fine chemical industries, especially in the pharmaceutical industry.

In this case, efficient end-of-pipe waste management is required instead of direct discharge. In

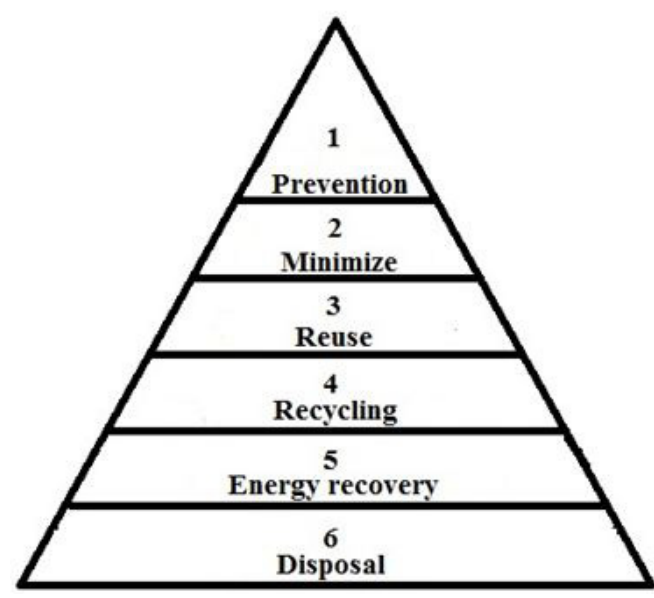

Figure 1. Waste management hierarchy diagram. [2] 
the case of end-of-pipe waste treatment methods, it is important to pay attention to any recoverable materials and their recycling [3].

Extractive heterogeneous-azeotropic distillation (EHAD) is a new distillation process developed by the Environmental and Process Engineering Research Group [4, 5], which already has several industrial implementations. The process has become a proven method for the treatment of process wastewater and waste solvents. The technique has proven the separating of highly non-ideal multicomponent azeotropic mixtures, which combines the advantages of extractive and heterogeneous-azeotropic distillations. In the process, the extractive agent (water) fed to the top of the column is used to break the azeotropic point, and the phase separator is used to separate the heterogeneous-azeotropic. The general schema of EHAD system is illustrated in Figure 2.

Figure 3 illustrates the equilibrium shifting effect of the addition of water on vapour-liquid equilibrium diagram of the mixture of ethanol (EtOH) and ethyl acetate (EtAc). It can be seen that by adding a given amount of extractive agent, the separation can be made quasi-ideal.

It should be emphasized that the EHAD process is advantageous because no new azeotrope is formed, since the water used as the extractive agent is already present in the mixture to be separated [6]. The waste solvents, which can be considered as three-component (ternary) or four-component (quaternary) mixtures, can be separated into binary component pairs by the process, which can be separated into their components in further, already simpler distillation columns $[7,8]$.

\section{Materials and methods}

In the specific task, the separation of a four-component mixture of industrial origin (Water - Ethyl alcohol - Methyl ethyl ketone - Ethyl acetate) was investigated.

Reliable vapour-liquid equilibrium data are essential to perform proper distillation calculations. In this regard, it is expedient to collect information from databases. The Gmehling-Onken VLE series has become the most widespread in professional sectors [9]. Table 1 lists the azeotropic cases of the solvent mixture to be investigated. It can be seen that it has 6 binary and 3 ternary azeotropic, so the separation behaviour has non-ideal circumstance and therefore requires complex treatment procedure.
Table 1. Azeotropic cases and boiling temperatures of quaternary Water - Ethyl alcohol-Methyl ethyl ketone (MEK) - Ethyl acetate mixture [9]

\begin{tabular}{|c|c|c|c|}
\hline \multicolumn{2}{|c|}{ Azeotropic cases } & \multicolumn{2}{c|}{ Boiling temp. [ $^{\circ} \mathbf{C}$ ] } \\
\hline Water & EtAc & & $70.4-72.3$ \\
\hline Water & MEK & & $73.7-73.8$ \\
\hline Water & EtOH & & $78.0-78.3$ \\
\hline EtOH & EtAc & & $70.9-72.1$ \\
\hline EtOH & MEK & & $74-75$ \\
\hline EtAc & MEK & & $76.4-77.1$ \\
\hline Water & EtOH & EtAc & $70.2-70.4$ \\
\hline Water & EtOH & MEK & 73 \\
\hline Water & EtAc & MEK & 71.1 \\
\hline
\end{tabular}

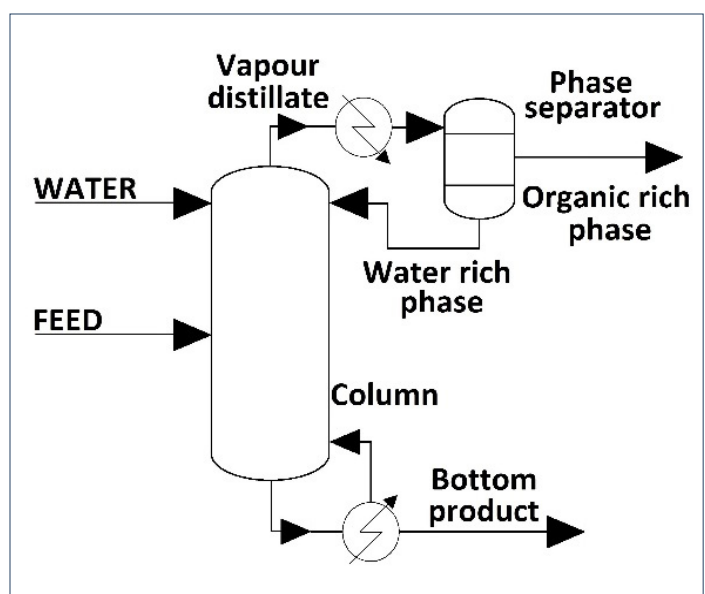

Figure 2. The general scheme of extractive heterogeneous-azeotropic distillation (EHAD). [4]

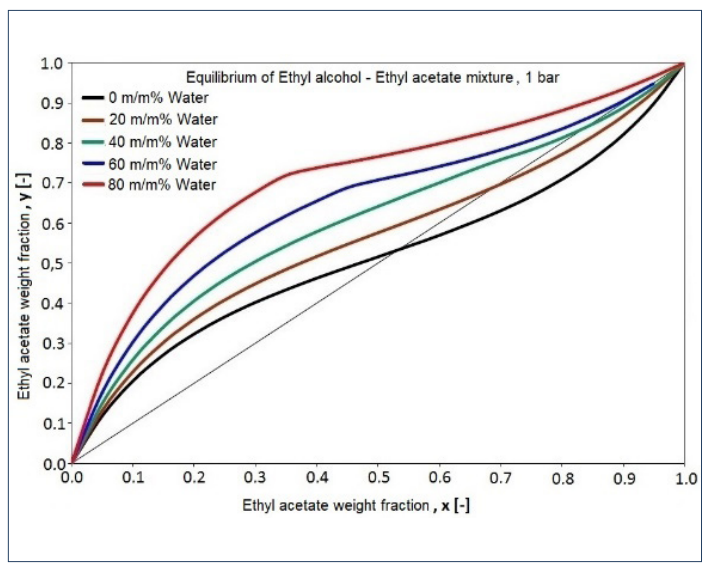

Figure 3. Equilibrium of Ethyl alcohol (EtOH) and Ethyl acetate (EtAc) with water addition. [5] 
The aim of this work was to decompose the quaternary mixture into azeotropic pairs. To solve this problem, water was pumped as extractive agent into the top of the column. Thus, a mixture of ethyl alcohol and water was formed as the bottom product of the column and its alcohol content was further enriched in another column. The twophase distillate product of the EHAD column was condensed in a phase separator. The water-rich lower phase was mixed with the extractive agent, and the non-alcoholic product was available in the upper phase.

The calculations were performed in a professional process simulator, in the ChemCAD software package. SCDS type columns and LLV Flash module as the phase separator were chosen. During optimization, the theoretical plate number of columns was changed. In addition, the variation of the water supply current in the case of the EHAD column was also investigated [10-12]. The four-component solvent mixture was fed into the middle of the column in each case. Furthermore, the temperature in the phase separator was adjusted to $20^{\circ} \mathrm{C}$. The correctness of these settings was confirmed by our previous research works $[4,5]$.

Figure 4 shows the separation structure in the process simulator.

Figure 5 illustrates the theoretical structure of the separation of the four-component mixture in tetrahedral representation, where apex 4 of the tetrahedron represents the pure components. In addition, various azeotropic compositions are depicted.

\section{Results and discussion}

Table 2 shows the optimal separation parameters for the HEAD column.

The results show that at least six times the amount of water added is required to meet the desired expectations. This high ratio to feed is realistic and is consistent with our previous findings that more water is required to separate more complex mixtures of many binary and ternary azeotropes [4].

It is important to emphasize that the most important factor in terms of operating costs in the case of distillation separations is the steam requirement, so it is worth striving to minimize this. Figure 6 illustrates the evolution of the theoretical plate count between the reboiler duty and the minimum required extractive agent. It can be seen that the two values correlate with each other, and after the theoretical plate number of 30
Table 2. The results of EHAD column (F: feed, D: distillate product, $W$ : bottom product).

\begin{tabular}{|c|c|c|c|c|}
\hline $\begin{array}{c}\text { Solvent mix- } \\
\text { ture }\end{array}$ & F & $\begin{array}{c}\text { Extractive } \\
\text { agent }\end{array}$ & $\begin{array}{c}\text { D-Upper } \\
\text { phase }\end{array}$ & W \\
\hline Water $[\mathrm{m} / \mathrm{m} \%]$ & 10 & 100 & 8.4 & 91.3 \\
\hline EtOH $[\mathrm{m} / \mathrm{m} \%]$ & 21 & 0 & 0 & 8.7 \\
\hline MEK $[\mathrm{m} / \mathrm{m} \%]$ & 32 & 0 & 40.3 & 0 \\
\hline EtAc $[\mathrm{m} / \mathrm{m} \%]$ & 37 & 0 & 51.3 & 0 \\
\hline Stream $[\mathrm{kg} / \mathrm{h}]$ & 500 & 3000 & 420 & 3080 \\
\hline Temp. $\left[{ }^{\circ} \mathrm{C}\right]$ & 20 & 20 & 70.9 & 92.7 \\
\hline
\end{tabular}

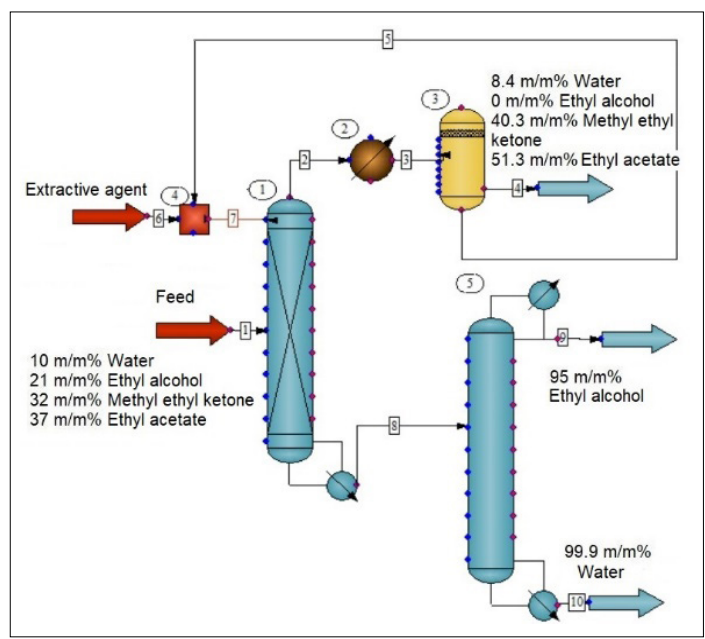

Figure 4. Separation of quaternary Water - Ethyl alcohol - Methyl ethyl ketone - Ethyl acetate mixture in process simulator

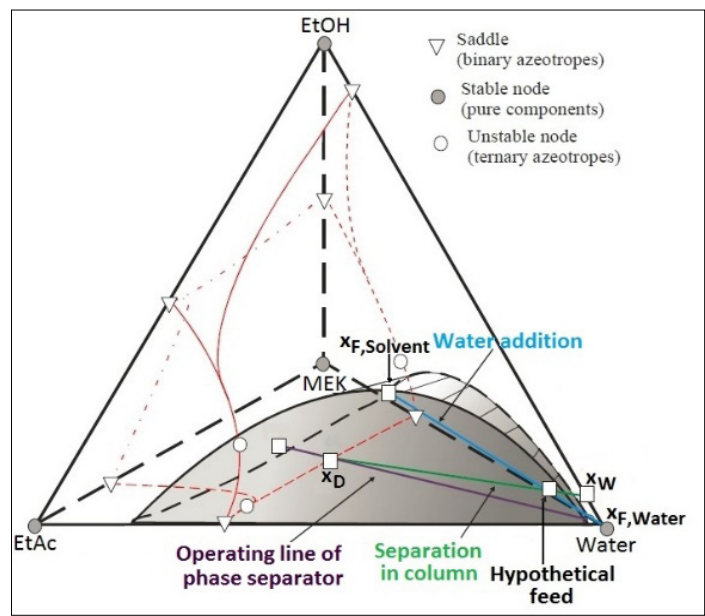

Figure 5. Separation of quaternary Water - Ethyl alcohol - Methyl ethyl ketone - Ethyl acetate mixture in tetrahedron $\left(x_{D}\right.$ : distillate composition, $x_{F}$ : feed composition, $x_{W}$ : bottom product composition) [13] 


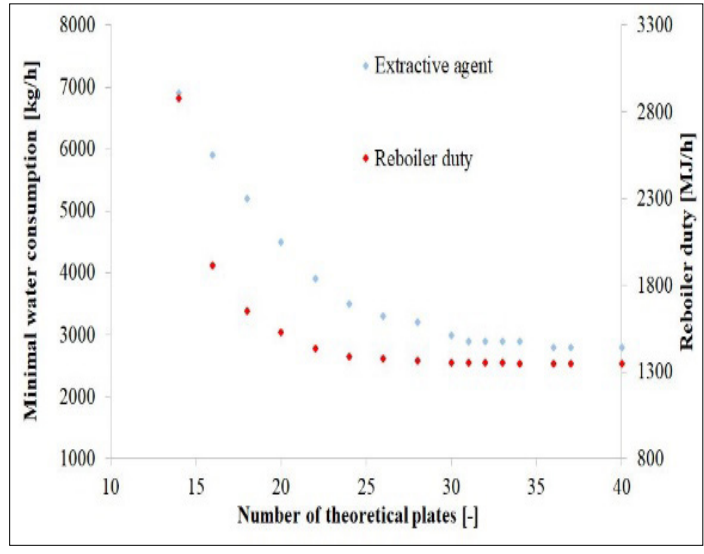

Figure 6. The theoretical number of plates in the function of reboiler duty and minimum water consumption.

there is no significant change. Thus, in the case of the EHAD column, the theoretical plate number of 30 can be considered optimal. In the case of larger column, we did not perceive significant change in the improvement of the compositions either, therefore it did not make sense to increase the size of the column in terms of investment costs.

In the case of the alcohol enrichment column, a nearly azeotropic distillate product was obtained in a column with theoretical plate number of 10 using a reflux ratio of 5 .

\section{Conclusions}

According to the calculations, it can be stated that the complex distillation method is suitable for the separation of highly non-ideal mixtures. For other mixtures with similar behaviour, the method can be generalized. The distillate product can also be further enriched if possible, but even less complex methods can be effective, because azeotropic decomposition has been achieved. The process also follows the principles of circular economy, which allows components to be recycled within the factory, all with the minimum equipment and energy required for the task.

\section{Acknowledgements}

This publication was supported by the János Bolyai Research Scholarship of the Hungarian Academy of Sciences, NTP-NFTÖ-20-B-0095 National Talent Program of the Cabinet Office of the Prime Minister, OTKA 128543 and 131586. This research was supported by the European Union and the Hungarian State, co-financed by the European Regional Development Fund in the framework of the GI-
NOP-2.3.4-15-2016-00004 project, aimed to promote the cooperation between the higher education and the industry. The research reported in this paper and carried out at the Budapest University of Technology and Economics has been supported by the National Research Development and Innovation Fund (TKP2020 National Challenges Subprogram, Grant No. BME-NC) based on the charter of bolster issued by the National Research Development and Innovation Office under the auspices of the Ministry for Innovation and Technology.

\section{References}

[1] Toth A. J.: Hulladékgazdálkodás a vegyiparban. Typotex, Budapest, 2020.

[2] Mizsey P., Tóth A. J.: Ipari ökológiai elvek alkalmazása technológiai hulladékvizek fiziko-kémiai módszerekkel történö kezelésénél. Ipari Ökológia, 1/1. (2012) 101-125.

[3] Brinkmann T., Santonja G. G., Yükseler H., Roudier S., Sancho L. D.: Best Available Techniques (BAT) Reference Document for Common Waste Water and Waste Gas Treatment/Management Systems in the Chemical Sector. Riport, Publications Office of the European Union, 2016.

[4] Toth A. J., Szanyi A., Koczka K., Mizsey P.: Enhanced Separation of Highly Non-Ideal Mixtures with Extractive Heterogeneous-Azeotropic Distillation. Separation Science and Technology, 51/7. (2018) 1238-1247.

https://doi.org/10.1080/01496395.2015.1107099

[5] Toth A. J.: Comprehensive Evaluation and Comparison of Advanced Separation Methods on the Separation of Ethyl Acetate-Ethanol-Water Highly Non-Ideal Mixture. Separation and Purification Technology, 224. (2019) 490-508. https://doi.org/10.1016/j.seppur.2019.05.051

[6] Toth A. J., Szilagyi B., Haaz E., Solti Sz., Nagy T., Szanyi A., Nagy J., Mizsey P.: Enhanced Separation of Maximum Boiling Azeotropic Mixtures with Extractive Heterogeneous-Azeotropic Distillation. Chemical Engineering Research and Design, 147. (2019) 55-62. https://doi.org/10.1016/j.cherd.2019.05.002

[7] Haaz E., Szilagyi B., Fozer D., Toth A. J.: Combining Extractive Heterogeneous-Azeotropic Distillation and Hydrophilic Pervaporation for Enhanced Energetic Separation of Non-Ideal Ternary Mixtures. Frontiers of Chemical Science and Engineering, 14/5. (2020) 913-927. https://doi.org/10.1007/s11705-019-1877-1

[8] Toth A. J., Szanyi A., Haaz E., Mizsey P.: Separation of Process Wastewater with Extractive Heterogeneous-Azeotropic Distillation. Hungarian Journal of Industry and Chemistry, 44. (2016) 29-32. https://doi.org/10.1515/hjic-2016-0003

[9] Gmehling J., Onken U., Rarey-Nies J. R.: VaporLiquid Equilibrium Data Collection. Dechema, Virginia, 1978. 
[10] Skiborowski M., Harwardt A., Marquardt W.: Conceptual Design of Distillation-Based Hybrid Separation Processes. Annual Review of Chemical and Biomolecular Engineering, 4. (2013) 45-68. https://doi.org/10.1146/annurev-chembioeng-061010-114129

[11] Gorak A., Sorensen E.: Distillation: Fundamentals and Principles. Elsevier Science \& Technology, Dortmund, London, 2014.
[12] Doherty M.F., Malone M.F.: Conceptual Design of Distillation Systems. McGraw-Hill, New York, 2001.

[13] Toth A. J.: Liquid Waste Treatment with Physic-chemical Tools for Environmental Protection, PhD-dolgozat, Budapest, BME, 2015. 